\title{
Editorial
}

\section{Memória - história e homenagem}

Quando um pesquisador está desenvolvendo um trabalho de investigação, é interessante que divulgue seus resultados e conclusões para o restante da comunidade científica. Desta forma, a ciência é conhecimento, arte, habilidade. Conjunto organizado de conhecimentos relativos à determinada área do saber, que se obtém através de leituras, estudos, instrução, erudição. Conhecimento prático para uma dada finalidade.

Com o advento da imprensa com Gutenberg, as academias resolveram publicar trabalhos e debates em revistas periódicas. A primeira delas foi o Journal des Savants - Jornal dos Sábios, fundado na França em 1662, e que deu origem ao uso do nome "journal”, diário em francês, para designar as revistas científicas. Logo depois, a Royal Society, celebrando 350 anos agora em 2010 , fundou a revista oficial da academia, o famoso Philosophical Transactions, que é a mais antiga revista científica, em circulação até hoje. As academias italianas também foram pioneiras, com os Saggi, a publicação da Accademia del Cimento. Em meados do Século XVII, portanto, estava pronto e acabado o atual modelo de comunicação científica vigente até hoje. Gradativamente o latim foi substituído nessas revistas pelo inglês, pelo italiano, francês e alemão, que se tornaram os idiomas da ciência; e as cartas informais entre cientistas se institucionalizaram na forma de Letters ou Léttres, publicadas nas revistas, conforme descrito por Renato Sabbatini.

Onde quer que exista um grupo de pessoas interessado num determinado assunto e um indivíduo ou organização com motivação suficiente para com ele se comunicar, existe uma revista que estabelece a ponte entre ambos.

Nesta linha de entendimento, surgiu a idéia de criação das publicações da SBCTA, iniciadas em 1967 com o Boletim de edição quadrimestral, cujos editores eram André Tosello e Ruth S. Garruti. O último Boletim foi editado em dezembro de 2003.

A Revista Ciência e Tecnologia de Alimentos começou a ser editada em 1981, inicialmente como revista semestral com publicação de 5 artigos por número, cujos primeiros editores foram Franco Maria Lajolo e Ciro Gonçalves Teixeira. Daí em diante, seguiu-se uma sucessão de editores que vieram se alternando de gestão em gestão da Diretoria da Sociedade.

Conforme informações fornecidas pela Secretária Executiva da SBCTA, Carmen Silvia Juliani Frizão, e pelo Assistente Editorial, Marcos Luis Alves, descrevemos a seguir uma descrição sobre as trajetórias do Boletim da Sociedade Brasileira de Ciência e Tecnologia de Alimentos e da Revista Ciência e Tecnologia de Alimentos.

Sobre o Boletim, seguem alguns detalhes:

1) O Boletim Informativo (como era chamado) teve início em setembro de 1967 (este foi o n 1 ) e seu conteúdo continha era:

- Lista de presença à Reunião de Fundação da SBCTA (pág.1);

- Resumo da Ata da Reunião de Fundação da SBCTA (pág. 3);

- Documento assinado em Varsóvia que constituiu o Comitê Latino-Americano de Tecnologia de Alimentos (pág. 6); e

- $1^{\text {a }}$ Reunião da Diretoria (pág. 7):

- Presidente - Walter Joaquim Santos

- $1^{\circ}$ Vice-presidente - Cyro Gonçalves Teixeira

- $2^{\circ}$ Vice-presidente - Paulo A.L. de Aguiar

- $3^{\circ}$ Vice-presidente - Aymar Baptista Prado

- $1^{\circ}$ Secretário - José Pio Nery

- 2o Secretário - Jorge Leme Júnior

- $1^{\circ}$ Tesoureiro - Roberto Hermínio Moretti

- 20 Tesoureiro - José Luiz L. Barreto

- Bibliotecária - Ruth S. Garruti.

2) O Boletim Informativo $n^{\circ} 2$ de Dezembro/1967 continha:

- Assembleia Geral Extraordinária da SBCTA (pág. 1);

- Comissões Técnicas (pág. 2);

- Notícias USAID (pág. 2);

- Novo Tesoureiro (pág. 3);

- Curso para supervisores de processamento industrial (pág. 3):

- A Diretoria era a mesma do $n^{\circ} 1$.
3) Quanto à periodicidade:

- 1967 - volumes 1 e 2

- 1968 - volumes 3, 4, 5 e 6

- 1969 - volumes 7, 8, 9, e 10

- 1970 - volumes $11,12,13$ e 14

- 1971 - volumes 15,16, 17 e 18

- 1972 - volumes 19, 20, 21 e 22 (volume 22 com 55 páginas)

- 1973 - volumes $23,24,25$ e 26

- 1974 - volumes $27,28,29$ e 30

- 1975 - volumes $31,32,33$ e 34

- 1976 - volumes 35, 36, 37 e 38 (a partir de 1976 a capa mudou)

- 1977 - volumes 39, 40, 41 e 42

- 1978 - volumes 43, 44, 45 e 46

- 1979 - volumes $47,48,49$ e 50

- 1980 - volumes 51, 52, 53 e 54

- 1981 - volumes 15(1), 15(2), 15(3) e 15(4) (a partir de 1981 a capa mudou novamente e a numeração dos volumes também)

- 1982 - volumes 16(1), 16(2), 16(3) e 16(4)

- 1983 - volumes 17(1), 17(2), 17(3) e 17(4)

- 1984 - volumes 18(1), 18(2), 18(3) e 18(4)

- 1985 - volumes 19(1), 19(2), 19(3) e 19(4)

- 1986 - volumes 20(1/2) e 20(3/4) (saíram apenas estes dois volumes) 
- 1987 - volumes 21(1), 21(2) e 21(3/4) (saíram apenas três volumes)

- 1988 - volumes 22(1/2) e 22(3/4) (saíram apenas 2 volumes)

- 1989 - volumes 23(1/2) e 23(3/4)

- 1990 - volumes $24(1 / 2)$ e 24(3/4)

- 1991 - volumes 25(1), 25(2) (o tamanho do Boletim mudou, ficou no formato da Revista e saíram apenas 2 volumes)

- 1992 - volumes 26(1) e 26(2)

- 1993 - volumes 27(1) e 27(2)

- 1994 - volumes 28(1) e 28(2)

- 1995 - volumes 29(1) e 29(2)

- 1996 - volumes 30(1) e 30(2)

- 1997 - volumes 31(1) e 31(2)

- 1998 - volumes 32(1) e 32(2)

- 1999 - volumes 33(1) e 33(2) (a capa mudou novamente)

- 2000 - volumes 34(1) e 34(2)

- 2001 - volume $35(1 / 2)$

- 2002 - volumes 36(1) e 36(2) (a capa mudou novamente)

- 2003 - volumes 37(1), 37(2) e 37(suplemento) (que foi o último Boletim, e foi editado em dezembro/2003 com 20 artigos e 128 páginas).

Agora sobre a Revista, seguem alguns pontos interessantes:

1) A $1^{\text {a }}$ Revista da SBCTA foi editada em 1981, volume $1 n^{\circ} 1$ páginas 1-72, jan/jun, com 5 artigos. Sumário:

a) Resfriamento de polpas semiconcentradas em tambores de 200 litros (pág.1)

b) Extração e avaliação da sacarose sintetase, invertase e UDPGpirofosforilase de bananas, com prevenção dos danos causados por fenóis e derivados (pág.23)

c) Secagem de micro-organismos em forno de micro-ondas. IIIInfluência da granulometria, da espessura inicial da amostra e da potência na secagem de leveduras (pág. 37)

d) Rapid gas-liquid chromatographic procedure for determination of glycerol and oil in corn grits (pág.51)

e) $\beta$-Galactosidase de Scopulariopsis sp: Imobilização em resina fenol-formaldeído (Duolite) e sua eficiência na hidrólise de lactose em Soro de leite (pág.65) - o qual um dos autores é a de autoria da atual $1^{\text {a }}$. Vice Presidente Prof ${ }^{\mathrm{a}}$. Gláucia Maria Pastore com o Prof. Yong K. Park.

2) Quanto à periodicidade:

- 1981 - volumes 1(1) e 1(2)

- 1982 - volumes 2(1) e 2(2)

- 1983 - volumes 3(1) e 3(2)

- 1984 - volumes 4(1) e 4(2)

- 1985 - volumes 5(1) e 5(2)

- 1986 - volumes 6(1) e 6(2)

- 1987 - volumes 7(1) e 7(2)

- 1988 - volumes 8(1) e 8(2)

- 1989 - volumes 9(1) e 9(2)

- 1990 - volumes $10(1)$ e $10(2)$

- 1991 - volumes 11(1) e 11(2)
- 1992 = volumes 12(1) e 12(2) (a partir de 1992 o tamanho da revista foi alterado para o tamanho atual)

- 1993 - volumes 13(1) e 13(2)

- 1994 - volumes 14(1), 14(2) e 14(suplemento)

- 1995 - volumes 15(1), 15(2) e 15(3)

- 1996 - volumes 16(1), 16(2) e 16(3)

- 1997 - volumes 17(1), 17(2), 17(3) e 17(4)

- 1998 - volumes 18(1), 18(2), 18(3) e 18(4)

- 1999 - volumes 19(1), 19(2) e 19(3)

- 2000 - volumes 20(1), 20(2) e 20(3)

- 2001 - volumes 21(1), 21(2) e 21(3)

- 2002 - volumes 22(1), 22(2) e 22(3) (a partir de 2002 a cor da capa foi alterada para azul)

- 2003 - volumes 23(1), 23(2), 23(3) e 23(suplemento)

- 2004 - volumes 24(1), 24(2), 24(3) e 24(4)

- 2005 - volumes 25(1), 25(2), 25(3) e 25(4)

- 2006 - volumes 26(1), 26(2), 26(3) e 26(4)

- 2007 - volumes 27(1), 27(2), 27(3), 27(4) e 27(suplemento)

- 2008 - volumes 28(1), 28(2), 28(3), 28(4) e 28(suplemento) (a partir de 2008 a cor da capa foi alterada para branco)

- 2009 - volumes 29(1), 29(2), 29(3) e 29(4)

- 2010 - volumes 30(1), 30(2) e 30(suplemento)

Os editores que trabalharam e contribuíram até o momento com a Revista seguem abaixo:

Volumes 1-5 (1981-1985)

- Franco Maria Lajolo

- Ciro Gonçalves

Volumes 6-8 (1986-1988)

- José Tadeu Jorge

- Franco Maria Lajolo

Volumes 9-10 (1989-1991)

- Eidiomar Angelucci

- Franco Maria Lajolo

Volumes 11-12 (1991-1992)

- Maria Aparecida P. Campos

- Maria Cristina R. Belda

Volumes 13-14 (1993-1994)

- Maria Aparecida P. Campos

- Marília Oetterer

Volumes 15-18 (1995-1998)

- Marília Oetterer

- Maria Angela de Almeida Meireles

Volumes 19-20 (1999-2000)

- Marilene de Vuono Camargo Penteado

- César Francisco Ciacco

Volumes 21-22 (2001-2002)

- César Francisco Ciacco

- Luis Carlos Trugo 
Volumes 23-24 (2003-2004)

- Franco Maria Lajolo

- Marilene de Vuono Camargo Penteado

Volumes 25-26 (2005-2006)

- Nelcindo Nascimento Terra

- Suzana Caetano da Silva Lannes
Volumes 27-28 (2007-2008)

- Suzana Caetano da Silva Lannes

- Elza Iouko Ida

Volumes 29-30 (2009-2010)

- Suzana Caetano da Silva Lannes

- Marilde Terezinha Bordignon Luiz

Além dos nomes acima, outros tantos vêm contribuindo com a Revista, destacando-se os ex-Presidentes da Sociedade e alguns membros do seu Corpo Editorial.

Desta forma, relatamos um pouco do histórico das publicações da SBCTA, principalmente da destacando-se a Revista que ainda continua em circulação após quase 29 anos, significando um patrimônio da Ciência e Tecnologia de Alimentos no País.

Suzana Caetano da Silva Lannes

Editora-chefe 